\title{
Pyrethroid resistance in the dengue vector Aedes aegypti in Southeast Asia: present situation and prospects for management
}

\author{
Zheng Hua Amelia-Yap ${ }^{1 *}$, Chee Dhang Chen², Mohd Sofian-Azirun² and Van Lun Low ${ }^{1 *}$
}

\begin{abstract}
Human arboviral diseases transmitted by Aedes aegypti such as dengue, Zika, chikungunya and yellow fever remain global public health threats to date. Of these diseases, dengue fever is particularly prevalent in Southeast Asia. Relentless vector control efforts are performed to curtail disease transmissions through which pyrethroid insecticides are broadly used as the first line of defense to control Ae. aegypti, especially in the course of disease outbreaks. Here, we compile the largest contemporary database for susceptibility profiles and underlying mechanisms involved in Ae. aegypti resistant to pyrethroids in Southeast Asia. The extensive use of pyrethroids inevitably elicit different levels of resistance to numerous populations despite the presence of geographical isolation. The most common mechanisms of pyrethroid resistance that have been identified in Ae. aegypti includes mutations in the voltage sensitive sodium channel gene (Vssc gene) and metabolic-mediated insecticide resistance. Aedes aegypti develops resistance to pyrethroids by acquisition of one or several amino acid substitution(s) in this Vssc gene. Enzymes involved in metabolic-mediated detoxification (i.e. monooxygenases, glutathione-S-transferases and esterases) have been reported to be related to pyrethroid resistance but many specific contributory enzymes are not completely studied. An inadequate amount of data from some countries indicates an urgent need for further study to fill the knowledge gaps. Perspectives and future research needs are also discussed.
\end{abstract}

Keywords: Pyrethroids, Insecticide resistance, Knockdown resistance, kdr, Metabolic-mediated resistance

\section{Background}

Dengue virus (DENV) and other arboviruses such as Zika virus, chikungunya virus and yellow fever virus are transmitted by Aedes aegypti. This highly adapted species thrives in urban and suburban areas. Effective control of Ae. aegypti is absolutely challenging when this species has deep-rooted and spread extensively in disease-endemic regions. With a lack of safe and effective treatment or vaccine for Ae. aegypti-borne diseases to date, tactics in suppressing Ae. aegypti continue to be the cornerstone in preventing dengue transmission and outbreak control.

An effective vector prevention to transiently remove Ae. aegypti involves several strategies such as eliminating potential mosquito breeding sites, applying chemical

\footnotetext{
* Correspondence: ame_lia1031@hotmail.com; vanlun_low@um.edu.my

${ }^{1}$ Tropical Infectious Diseases Research \& Education Centre (TIDREC),

University of Malaya, 50603 Kuala Lumpur, Malaysia

Full list of author information is available at the end of the article
}

insecticides and biological control. However, the most extensively practiced control for Ae. aegypti, owing to its high efficacy in regulating the populations with relatively rapid action, is the application of chemical insecticides. The use of multiple classes of synthetic insecticides has been largely practiced in vector control strategies, with pyrethroid-based formulations massively dominating the insecticide market worldwide.

To the authors' knowledge, there is no study to address the overall prevalence of pyrethroid resistance in Ae. aegypti in Southeast Asian countries. Therefore, this systematic review was carried out to determine related present situation to deliver datasets which will require in vector control management on improving public health of human population.

\section{Burden of pyrethroid resistance in Aedes aegypti}

Geographical expansion of Aedes aegypti has fostered the incidence of dengue fevers (DF) to gain an apparent 
increase worldwide, which put an estimation of almost half of the world's population at stake for the disease [1]. The most extensively practiced control for Ae. aegypti, owing to its high efficacy in regulating the populations with relatively rapid action, is the application of chemical insecticides [2]. Pyrethroid insecticides are currently being used extensively to control Ae. aegypti adults worldwide and constitute approximately $17 \%$ of the worldwide insecticide market share and 1.4 USD billion of global trades [3]. In general, pyrethroids are neurotoxins which modify the normal function of insect nerves and cause disruption at the Vssc gene by depolarizing neurons $[4,5]$, paralyzing and eventually killing the insect. Deltamethrin, cypermethrin, cyfluthrin, lambdacyhalothrin, permethrin, alpha-cypermethrin, pyrethrum, bifenthrin, d-phenothrin, z-cypermethrin and etofenprox are the major types of pyrethroids used, and that their treatments usually involve either residual or space spray [6]. Narrowing down to Southeast Asia, deltamethrin, permethrin, alpha-cypermethrin, cyfluthrin and lambdacyhalothrin are commonly employed in suppressing Ae. aegypti, particularly in Malaysia [7-9], Indonesia [10-12], Singapore [13-15] and Thailand [16-18]. All the onshelf insecticides available for vector control are obliged to apply cautiously to delay worldwide evolution of mosquito resistance.

Currently, insecticide resistance is one of the most severe issues facing mosquito control agencies. The loss of efficacy of pyrethroids may consequently bring high possibility of operational failure of Ae. aegypti-borne diseases control and subsequently lead to increased disease transmission. This will cause even larger capital to be invested into mosquito control programmes by the government in return, for examples, the development of new insecticides in terms of labors and costs, which may cause direct socio-economic impact to a country. Other than the commonly-reported adverse impacts on public health and environment, reports particularly on the economic cost of pyrethroid resistance in Ae. aegypti in Southeast Asia have not been presented. This is in large part due to the progression of operating and resource costs throughout the vector control programme since the first occurrence of control problems until complete control failures have not been described. To expedite the progress and execution of scientifically-sound policies of insecticide use, economic costs in Southeast Asian context are vital to be studied.

A need of new paradigm or choice to control Ae. aegypti is undeniably urgent, provided that the current vector control strategies in Southeast Asia resulted in the discovery of insecticide-resistant mosquito populations. The ultimate goal of a vector control programme should focus on the establishment of an efficient government-community partnerships that the community plays a fundamental character in implementing these programmes. However, it should also be stressed that the success of these programmes can only be accomplished if both parties are committed to implement procedures in assisting community participation in Ae. aegypti control.

\section{Pyrethroid resistance mechanisms}

Physiological resistance and behavioral avoidance of $A e$. aegypti to insecticides are two integral responses ascribed to the intensified implementations of chemicalbased control programmes. Physiological resistance implies the survival of mosquito victims under the exposure to chemical insecticides which would normally lead to complete death, comprising the most welldocumented mechanisms conferring resistance against pyrethroid insecticides in Ae. aegypti such as insensitivity of target site which causes knockdown resistance $(k d r)$ [19]; and metabolic detoxification via mixed function oxidases (P450 mediated monooxygenases), esterases and glutathione S-transferases (GSTs) [20]. Behavioral avoidance is the development of any change in the behavior of a mosquito to decrease the exposure of toxic substances or to escape lethal effect of insecticide, but this mechanism is easily overlooked [20]. Other than the aforementioned resistance mechanisms, insecticide resistance in Ae. aegypti is also mediated by cuticular resistance. Notes on each mechanism are described as follows.

\section{Behavioral avoidance}

In-depth behavioral avoidance studies in Ae. aegypti are scarce across Southeast Asia until now. A change in mosquitoes' feeding or resting behavior to minimize exposure to insecticides, this mechanism is generally categorized into direct contact excitation and non-contact spatial repellency [20]. Direct contact excitation (irritancy) is a phenomenon when mosquitoes escape from insecticide-exposed environment upon physical contact, while non-contact spatial repellency is when mosquitoes leaving the toxic area even before getting contact with a treated surface. Related behavioral avoidance studies of Ae. aegypti exposed to a range of pyrethroids have been inspected in Thailand, projected that average to strong irritancy have demonstrated in all tested populations when compared to repellency [21-24]. Despite the importance of behavioral responses of mosquitoes to insecticides contribute to the efficacy of chemicals, the relative complications of the assay designs, for instance, problems in differentiating between contact excitation and non-contact spatial repellency responses exerted in mosquitoes, lacking ideal statistical methods in analyzing data, and difficulties in 
introducing and removing test specimens, cause a dearth of information in this mechanism.

\section{Cuticular resistance}

Cuticle thickening is implicated in insecticide resistance by reducing the uptake of the insecticide that reaches the target site in response to the modification of chemical composition of the cuticle. In mosquitoes, cuticular resistance is often pointed out but related studies are insufficient. A recent study revealed that this mechanism may play a major role in the development of resistance where it normally happens simultaneously with other mechanism(s) [25], causing resistance to single or multiple insecticides [26]. It has been reviewed elsewhere that cuticle thickening is associated with metabolic detoxification whereby thicker cuticle causes gradual insecticide absorption rate that will increase the effectiveness of metabolic detoxification in Anopheles funestus [27]. Moreover, it is crucial to take note that insects with cuticular resistance will display resistance level of not more than 3-fold in comparison to susceptible insects, but the co-occurrence of other resistance mechanism will lead to a surge in insecticide resistance level markedly [28]. This is demonstrated by Anopheles gambiae in Benin [29] through which overexpression of cuticular genes and $\mathrm{P} 450$ genes gave rise to a relatively high resistance level. Cuticular resistance to pyrethroids is also characterized in Ae. aegypti [30] but there is a lack of similar report documented in Southeast Asia. The fact that this least-understood mechanism may play substantial role in resistance urges for immediate attention in investigating, particularly in pyrethroid-resistant Ae. aegypti.

\section{Knockdown resistance $(k d r)$}

Target site resistance in mosquitoes is related to either single or multiple mutations in target genes; for example, the Vssc gene which leads to $k d r$, mutations in the acetylcholinesterase (Ace-1) gene and GABA receptors [31, 32]. The most well-studied target site resistance for Ae aegypti is $k d r$ because it confers resistance against pyrethroids. The Vssc gene comprises four homologous domains and each of them contains six hydrophobic subunits (segments 1-6). In the past few decades, numerous mutations in the Vssc gene have been documented to be linked to $k d r$ in many insect disease vectors. The single point L1014F mutation in the domain II segment 6 (IIS6) was the foremost mutation associated with pyrethroid resistance identified. Thereafter, different substitutions of C, F, H, S or W at this position have been reported in a few mosquito species in the genera of Anopheles and Culex mosquitoes [33-36].

In Ae. aegypti mosquitoes, L1014 has yet to be identified but several different $k d r$ mutations have been detected in Southeast Asia; for examples, S989P, I1011M/V, V1016G/I and F1534C based on the mutation positions of house fly sodium channel [10, 37-41]. It is no surprise that more sodium channel mutations in resistant insects have been discovered taking the advantage of the convenience of molecular approach. Beside the identification of single point mutations, novel cooccurrence of mutations was also detected. As firstly reviewed by Brengues et al. [37], V1016G was closely related to S989P in Southeast Asian countries such as Indonesia, Myanmar, Thailand and Malaysia [9, 10, 39, 42], and this common phenomenon was believed to confer higher resistance. Co-occurrence of triple mutations V1016G, S989P and F1534C would result in even higher resistance to pyrethroids, as seen in Ae. aegypti populations from Myanmar [39]. The detection of these specific mutations, such as V1016G, S989P and F1534C, were affirmed to confer sodium channel resistance to pyrethroids and other associated mutations which are still yet to be inspected. It is very likely for the emergence of new $k d r$ mutations when pyrethroids remained to be the primary insecticide-based interventions in the control of Ae. aegypti. Hence, these detections act as a crucial role in resistance management of Ae. aegypti by observing the occurrence of pyrethroid resistance.

It is remarkable that despite two distinct substitutions occur at the same amino acid position, V1016G and V1016I display different geographical variations with dissimilar response of Ae. aegypti sodium channel to pyrethroids. V1016G has been detected in Southeast Asia [37, 39, 40, 43, 44] while V1016I has been found in North and South America [45-47]. In recent times, the V1016I mutation was detected in Vietnam [41] and V1016I along with F1534C was detected in Ghana that there may be presence of migration event [48]. The detection of these point mutations in Ae. aegypti strains in continents they have never existed before requires further validation to confirm if the resistance is caused by migration or de novo (new) mutations. The evolution and distribution of pyrethroid resistance in Ae. aegypti populations is relevant when their eggs can endure desiccation for an extended period that permit them to put human travel to good use.

\section{Metabolic-mediated insecticide resistance}

Metabolic resistance in Ae. aegypti involves alterations in a series of the expression of a complex group of enzymes, causing a rise in the detoxification process of insecticides. This resistance mechanism facilitates increased biodegradation of insecticides, with the help of enzymes such as GSTs, esterases and cytochrome P450 monooxygenases (P450 genes). A total of $160 \mathrm{P} 450$ genes, 49 GSTs and 26 esterases have been revealed in an international genome project of Ae. aegypti [49]. 
Among these, cytochrome P450 genes are the enzyme family highly responsible for the development of pyrethroid resistance in Ae. aegypti. Therefore, cytochrome P450 genes are of interest to study since they are capable in metabolizing xenobiotics such as drugs, plant toxins and insecticides. One of the most noteworthy characteristics of P450 genes linked to enhanced metabolic detoxification of insecticides is the detection of a significant rise in $\mathrm{P} 450$ proteins and $\mathrm{P} 450$ activity due to the overexpression of insecticide-resistant insects P450 genes, which is closely associated with the development of insecticide resistance [50,51]. However, identification of enzymes associated with insecticide resistance is difficult because of the presence of diverse group of $\mathrm{P} 450$ genes and high structural similarity in isoforms that makes identifying isoform related to resistance to be challenging. While molecular approaches in detecting Vssc gene mutations in pyrethroid-resistant Ae. aegypti are broadly documented, they are rare for P450 genes. CYP9 family has been involved in pyrethroid resistance in the dengue vector Ae. aegypti [52]. CYP9J22 and CYP9M9 were the two P450 genes found with the highest transcript level of the resistant populations [52]. On a global scale, the most frequently found $\mathrm{P} 450$ genes are CYP9M6, CYP6BB2, CYP9J26 and CYP9J28, which are commonly detected to be overexpressed in resistant strains in many studies, projecting their capability in metabolizing permethrin $[25,53,54]$.

Esterase hydrolysis of pyrethroids resulting in the detoxification process has assumed to involve in metabolic resistance in some cases. This mechanism encompasses a series of reaction, such as gene amplification, upregulation, and/or coding sequence mutations. However, published data on which exact esterases in contributing to the presence of pyrethroid-resistant Ae. aegypti populations in Southeast Asia continues to be scarce. Elevated levels of GSTs are also commonly associated with insecticide resistance. Most of the GSTs are made of a super family structure of cytosolic-dimeric enzymes that are grouped into a total of six classes, namely Delta, Epsilon, Omega, Sigma, Theta and Zeta [55]. The two largest classes of GSTs for insects are Delta and Epsilon, provided that Epsilon class is often involved with resistance [56]. In Ae. aegypti, there are basically a cluster of eight sequentially arranged genes that mapped genetically to chromosome 2, supercontig 1.291 in the Epsilon GST class [56]. Recently, microarray studies have discovered some additional members of this gene cluster with elevated levels in Ae. aegypti populations resistant to insecticides [52]. However, their roles in metabolizing insecticides like pyrethroids are yet to be determined. Although esterases and GSTs are usually found overexpressed in pyrethroid-resistant Ae. aegypti, the causal of specific enzymes to the resistant populations from each of the enzyme family are still largely unverified up to now especially in Southeast Asia.

It is indisputably important to investigate metabolicmediated insecticide resistance of Ae aegypti to pyrethroids since co-existence of more than one mechanism is likely to occur, especially the largest endemic sites of DF Southeast Asia. In addition, efforts should be put in to the development of new insecticides, taking these enzymes related to insecticide resistance into consideration in the span of design procedure.

\section{Present situation of pyrethroid susceptibility in Aedes aegypti in Southeast Asia}

Published literature with regards to the insecticide resistance profiles of Ae. aegypti against pyrethroids in most of the Southeast Asian countries are detailed as follows. Information were extracted from all publications documenting mortality, lethal concentration $\left(\mathrm{LC}_{50}\right)$ and knockdown time $\left(\mathrm{KT}_{50}\right)$ from bioassays of Ae. aegypti mosquito populations using merely pyrethroids. Since our main emphasis was chiefly placed on studies assaying pyrethroids against Ae. aegypti, other classes of insecticides tested and species other than Ae. aegypti found in the same publication were excluded and not reviewed in this study. $K d r$ assays used to observe the effect of control tactics on pyrethroid resistance were also studied. Distribution of different $k d r$ mutations in Ae. aegypti in Southeast Asia are summarized in Table 1. Approaches employed to detect insecticide resistance when it first presents may allow timely associated management actions. Since there is a deficiency of studies on the metabolic resistance in some of the Southeast Asian countries, genes identified as overexpressed in resistant populations are reported only in countries with related publications. Publications from all years were retrieved, considered and incorporated into the review. Knowledge gaps which required attention are also identified in this review.

\section{Cambodia}

Although dengue is a major health concern in Cambodia [57], there are merely two known studies evaluating insecticide resistance status of Ae. aegypti in the country. The first related study was carried out using temephos (an organophosphate) at Phnom Penh and Kampong Cham in accordance with WHO standard bioassays [58]. Mosquito populations from Phnom Penh revealed temephos resistance whereas the latter populations were susceptible [58]. It is believed that temephos resistance in Phnom Penh populations led to another more comprehensive study encompassing Phnom Penh, Siem Reap, Kampong Cham and Battambang using both temephos and pyrethroids (permethrin and deltamethrin). Resistance to permethrin and deltamethrin were reported in Ae. aegypti populations from all the aforementioned 
Table 1 Distribution of different $k d r$ mutations in Ae. aegypti in Southeast Asia

\begin{tabular}{|c|c|c|}
\hline Country & Mutation & Reference \\
\hline \multirow[t]{2}{*}{ Cambodia } & F1534C & {$[60,61]$} \\
\hline & V1016G & [61] \\
\hline \multirow[t]{4}{*}{ Indonesia } & V1016G & {$[10,37,44,61,63,66]$} \\
\hline & F1534C & {$[10,44,61,63,66]$} \\
\hline & S989P & {$[10,44,63]$} \\
\hline & V1016G/S989P & {$[10,44,63]$} \\
\hline \multirow[t]{2}{*}{ Laos } & V1016G & [43] \\
\hline & F1534C & [43] \\
\hline \multirow[t]{2}{*}{ Malaysia } & V1016G & [9] \\
\hline & F1534C & [9] \\
\hline \multirow[t]{6}{*}{ Myanmar } & V1016G & {$[39,61]$} \\
\hline & S989P & [39] \\
\hline & F1534C & {$[39,61]$} \\
\hline & V1016G/S989P & [39] \\
\hline & V1016G/F1534C & [39] \\
\hline & V1016G/F1534C/S989P & [39] \\
\hline Philippines & na & \\
\hline \multirow[t]{2}{*}{ Singapore } & F1534C & {$[25,93]$} \\
\hline & V1016G & {$[25,40,93]$} \\
\hline \multirow[t]{5}{*}{ Thailand } & I1011V & {$[40]$} \\
\hline & F1534C & {$[60,61,108]$} \\
\hline & S989PN1016G & {$[42,112]$} \\
\hline & V1016G & {$[37,40,61]$} \\
\hline & V1016G/F1534C/S989P & [109] \\
\hline Timor-Leste & na & \\
\hline \multirow[t]{4}{*}{ Vietnam } & V1016l & [41] \\
\hline & I1011V & [126] \\
\hline & F1534C & [126] \\
\hline & V1016G & {$[126]$} \\
\hline
\end{tabular}

Abbreviation: na, not available

study sites [59]. Therefore, a nationwide assessment is recommended to examine pyrethroid resistance in Ae. aegypti since Cambodia is a country bordering the dengue-endemic countries Thailand, Laos and Vietnam, so as to develop effective vector control methods to halt the spread of DF.

In Cambodia, the point mutations of the $k d r$ gene related with pyrethroid resistance of Ae. aegypti were analyzed alongside with samples from other Southeast Asia countries in two international studies. The F1534C mutation was detected in the first study [60] whereas C1534 mutant alleles (with VV/CC patterns) were detected in the second study [61]. Further detection is highly sought after due to a deprived of nationwide studies that may possibly lead to the discovery of other unreported point mutations of the $k d r$ gene. This helps to understand the nature of pyrethroid resistant in $A e$. aegypti in this country, given that dengue is endemic year-round in Cambodia. Biochemical mechanisms of Ae. aegypti to pyrethroid resistance have not been reported.

\section{Indonesia}

After a first occurrence in 1968, countless outbreaks of DF and dengue haemorrhagic fever (DHF) cases transmitted by the primary vector Ae. aegypti mosquitoes have dramatically increased in recent years. The latest statistic showed 71,668 DF human cases in 2015 [62], covering all 34 provinces of the country. In Indonesia, pyrethroids have been broadly used since the 1980s against Ae. aegypti but there has been a dearth of knowledge on published information. Earlier, some pioneer works reported that Ae. aegypti populations from West Java (Ciamis, Purwakarta and Bogor) and Bandung were resistant to permethrin, lambda-cyhalothrin, cypermethrin and d-allethrin [11,37]. Despite high $\mathrm{LT}_{90}$ values being recorded [11], their resistant status regrettably should not be concluded. The standard susceptible laboratory strain used as a control in the study appeared to be resistant, led to an uncertainty of the resistant status. More recently, published data showed the presence of pyrethroid resistance in Ae. aegypti even after approximately 10 years of the pioneer studies $[10,44,63]$. Their susceptibility profiles suggested similar trends of resistance to pyrethroids $[10,44,63]$, signifying comparable patterns of insecticide usage in these sampling sites.

Over the years, biochemical studies have acknowledged the role of detoxifying enzymes in the development of pyrethroid resistance in Ae. aegypti. The first small-scale test in determining the resistance mechanisms involved in pyrethroid-resistant Ae. aegypti was accomplished in 2007, comprising strains from Bandung, Palembang and Surabaya [12]. Adult Ae. aegypti from Bandung demonstrated the highest resistance level to both permethrin and deltamethrin, corresponding to the high levels of activity of enzymes tested, i.e. oxidases, esterase A and esterase B, that play roles in the development of resistance to pyrethroids. In contrast, another study [64] showed that larvae from most sampling sites in Cimahi were still susceptible to pyrethroids although Bandung situates in absolutely close proximity to Cimahi. Adult susceptibility profile may greatly correlate with larval susceptibility profile in some cases $[7,65]$. However, it should be remembered that there is a difference between resistance score in larvae and adults because they may develop dissimilar resistant mechanisms through different mechanism pathways from larval to adult stages [14]. Thus, adult bioassay is still required to verify the resistance status. 
Other than the responsibility of detoxifying enzymes in the insecticide resistance mechanisms, mutations in the $V s s c$ gene should also be highlighted because they may act as markers for resistance monitoring. In Indonesia, $k d r$ profiling of Ae. aegypti had recorded three point mutations related to pyrethroid resistance, namely the S989P, V1016G and $\mathrm{F} 1534 \mathrm{C}$ mutations $[10,37,44,63,66]$. The discovery of the V1016G mutation was first reported by Brengues et al. [37] in the Semarang strain. Later, some findings were in agreement that all three mutations in Vssc gene were detected in Ae. aegypti populations from Yogyakarta, Central Java Province, Denpasar and Jakarta $[10,44,63,66]$. The V1016G mutation was most frequently detected in high frequencies, remarkably associated with permethrin and deltamethrin resistance in Ae. aegypti. Previous reports discovered relatively low frequency of the F1534C mutation, which did not demonstrate significant contribution to the resistance development of pyrethroids in Ae. aegypti $[10,44,63,66]$. As for the S989P point mutation, it generally co-occurred with the V1016G mutation, showing association on pyrethroid resistance development in Ae. aegypti. Furthermore, the frequency of the V1016G mutation occurred in Ae. aegypti in the Central Java has increased two-fold in just a decade, compared to a report generated earlier [37]. These preliminary detections of insecticide resistance will fundamentally aid in initiating appropriate control measures in delaying development of mosquito resistance, for instance rotation of insecticide or addition of catalyst to enhance the efficacy of insecticides in suppressing Ae. aegypti in Indonesia.

\section{Laos}

Compared to the neighboring countries, there is a scarcity of study on pyrethroid resistance in Ae. aegypti in Laos. The first DF outbreak was recorded in 1998 in Khammouane Province [67]. Although Ae. aegypti has been stated to be the main vector of numerous mosquito-related diseases in Laos [67, 68], with 22,772 cases of dengue reported during 2010 [69], there is only a single report investigating pyrethroid resistance status of Ae. aegypti in the country thus far. Samples were collected from five provinces and populations involved in the study identified high level of resistance against permethrin, which contrast with deltamethrin that exhibited high susceptibility in Ae aegypti [43]. Higher quantities of P450 genes were detected in field compared to reference strains but no particular $C Y P$ was mentioned. The frequencies of $k d r$ mutations were low for the V1016G mutation $(<0.36)$ but relatively higher for the F1534C mutation ( $>0.6$ for majority of places). With a total of 18 provinces available in Laos and a reliance upon pyrethroids in Ae. aegypti control after the official ban of DDT in 2010 [70], more comprehensive studies are needed in Laos, as this knowledge is fundamental in managing vector control programmes.

\section{Malaysia}

DF or DHF has been a critical public health concern in Malaysia at all times since the first outbreak in 1973. Regardless of extensive fogging operations with malathion in Malaysia as early as the 1970s, and followed by the replacement of pyrethroids like permethrin and deltamethrin in early 1998 until today [71], dengue remains number one infectious disease with a total of 101,357 cases reported in the country [72]. Numerous surveillance activities have been conducted to investigate insecticide susceptibility status of Ae. aegypti. The first study examining on the pyrethroid resistance level of $A e$. aegypti in Malaysia was accomplished in 2001, using field strains from Kuala Lumpur, Selangor, Negeri Sembilan, Johor, Kelantan and Pahang. The urban strain of Ae. aegypti from Kuala Lumpur showed the highest resistance to permethrin, validating the high levels of esterase compared to the laboratory strain [73]. This result was in agreement with the findings performed after almost a decade. Permethrin resistance persisted in field strains of Ae. aegypti collected from dengue-endemic areas of Kuala Lumpur [7]. Both larval and adult bioassays of the field strains confirmed the development of tolerance towards permethrin with several folds higher than the laboratory strain [7], indicating high reliability on chemical insecticides to control Ae. aegypti in an unprecedented scale at the dengue hotspots. Piperonyl butoxide (PBO) was also reported to be effective in enhancing the effectiveness of permethrin through which strong correlations were confirmed between $\mathrm{LC}_{50}$ or $\mathrm{LT}_{50}$ values and oxidase levels for all strains [7], implying the involvement of oxidase activity in causing permethrin resistance in this mosquito species.

Another similar study performed at dengue-prone sites of Selangor documented resistance and incipient resistance of Ae. aegypti to permethrin (mortality $\leq 80 \%$ ) and cyfluthrin (mortality 45-97.8\%), respectively [8]. Although cyfluthrin was not used by the municipal in vector control programme, fluctuated resistance was detected and this may be attributed to the role of $k d r$. Screening of $k d r$ is yet to be performed in Selangor but it has already accomplished and confirmed on the presence of $k d r$ in Kuala Lumpur [9], which is very close to Selangor. DDT resistance was also detected over the course of the study [8], further supporting the role of $k d r$ in both pyrethroid and DDT resistance due to the shared Vssc target site. GST activity exerted on DDT resistance has not been discovered in Malaysian mosquitoes including Ae. aegypti [71, 74]. The widespread of 
insecticide resistance pays full responsibility to failures in vector control programme. Aedes aegypti populations from mainland Penang were also highly resistant to lambda-cyhalothrin [75]. These outcomes were supported by the fact that pyrethroids have been broadly sprayed in the study areas for more than 10 years. Of several studies conducted in the country, insecticide susceptibility status of permethrin was often tested against Ae. aegypti in Malaysia because this insecticide is one of the main adulticides used in Malaysia [76]. Moreover, the development of permethrin resistance at a higher rate than malathion and temephos [77] might be closely associated with gene activation due to the exposure to insecticidal pressure.

More recently, despite discrepancies of insecticide susceptible status found in the field strains of Ae. aegypti from Kuala Lumpur, Penang, Johor Bharu and Kota Bharu tested against permethrin and deltamethrin, the mosquito strains from Kuala Lumpur remained to exhibit the highest resistance levels [9]. Synergist assays with $\mathrm{PBO}$ showed that metabolic resistance mechanisms played key role in certain strains. This particular study is the first report in Malaysia in characterizing the $k d r$ resistance in Malaysian populations of Ae aegypti. The V1016G and the F1534C mutations were detected, with the F1534C mutation closely associated with pyrethroid resistance whereas the V1016G mutation co-occurred to contribute to the additive effect of pyrethroid resistance in Malaysia [9]. A microarray-based genome-wide transcriptional analysis discovered that metabolic resistance of pyrethroid resistance in Ae aegypti populations is predominantly caused by overexpressed of the cytochrome P450 genes (CYP9J27, CYP6CB1, CYP9J26 and CYP9M4) [32]. However, more characterization work on the cytochrome P450 family must be carried out to understand the precise roles of these genes in contributing pyrethroid resistance in Ae. aegypti.

As far as we know, Malaysia is one of the two countries in Southeast Asia tested on the efficacies of the commercial mosquito coils against Ae. aegypti. The mosquito coil is one of the most extensively-used antimosquito household spatial repellents in Malaysia, accounting for the low costs and easy availability on-shelf countrywide [78-81]. In 1996, the first study assayed on the efficacies of mosquito coils containing active ingredients like d-allethrin $(0.2 \% \mathrm{w} / \mathrm{w})$ and d-trans allethrin $(0.1 \% \mathrm{w} / \mathrm{w})$ against laboratory Ae. aegypti were accomplished, revealing adequate knockdown effects but with minimal mortalities for both coils [78]. After almost a decade, a similar study was conducted with the use of $\mathrm{d}$-allethrin $(0.2 \%$ and $0.3 \% \mathrm{w} / \mathrm{w})$ and d-trans allethrin $(0$. $1 \%$ and $0.2 \% \mathrm{w} / \mathrm{w}$ ) on laboratory strain of Ae. aegypti [82]. Dosage increment of the active ingredients in mosquito coils, which are $0.3 \% \mathrm{w} / \mathrm{w}$ of $\mathrm{d}$-allethrin and $0.2 \%$ $\mathrm{w} / \mathrm{w}$ of $\mathrm{d}$-trans allethrin were proven to show higher repellent efficacies and mortality [82]. However, this result requires further verification on field strains in natural settings. In the past decades, efficacy studies were performed on the laboratory strains of Ae. aegypti. Until recently, insecticidal activities of Malaysian commercial coils have been assessed on field strains of Ae. aegypti in a nationwide-scale. Aedes aegypti from a total of 11 states were discovered to be resistant to mosquito coils containing active ingredients of d-allethrin, d-trans allethrin, metofluthrin and prallethrin, according to the resistance index recommended by the WHO [83]. Since there is a wide array of insecticides used intensively in the country to curtail disease transmission, either operations conducted by the Ministry of Health, private companies or even at household level [84], it is utmost important to assess regularly on the efficacies of insecticides used to guarantee effective vector control programme.

\section{Myanmar}

The first documented outbreak of DHF was in 1969 and then the outbreaks gradually increased to 12 out of 14 states in Myanmar [85]. This disease was documented with a high of 83,381 cases, causing 3243 deaths between 1970-1991 [85]. No sign of decrement in DHF incidence with 5621 cases in 2005 to an approximate two-fold of 11,049 cases in 2006 [86], despite persistent control efforts made by the Myanmar government since 1968 [85]. Although the significance of the disease requires immediate attention, there is only a single report on the ecological study of Ae. aegypti focusing on the southern part of Myanmar [86]. There is still an unavailability on the bioassay studies of the status of pyrethroid resistance in Ae aegypti in the country.

There is an absence of study to date, regarding the biochemical mechanisms of Ae. aegypti to pyrethroid resistance. In 2014, a project was initiated to evaluate the types and frequencies of point mutations of the $k d r$ gene related with pyrethroid resistance of Ae. aegypti. It was revealed that V1016G and S989P mutations were extensively scattered in Yangon city with high frequencies of $84.4 \%$ and $78.8 \%$, respectively [39]. Another widely scattered point mutation identified with relatively low allelic frequency of $21.2 \%$ was F1534C [39]. Other than three single point mutations were detected in Yangon city, three patterns of co-occurrence of point mutations were also identified with widely distributed homozygous V1016G/S989P mutations (65.7\%), as well as a small number of homozygous V1016G/F1534C mutations (2.9\%) and homozygous V1016G/F1534C/S989P (0.98\%) [39]. It should be noted that the observed types and frequencies of resistance alleles may be very well representing the Yangon city, as samples were collected from seven townships. 
However, it may not be a decent approximation of types and genotype frequencies of the country because the size of Yangon city $\left(598.75 \mathrm{~km}^{2}\right)$ is relatively small compared to Myanmar $\left(676,578 \mathrm{~km}^{2}\right)$. Therefore, sampling is needed throughout the country to ensure the surveillance of resistance genes in wild Ae aegypti populations are comprehended.

\section{Philippines}

There appears to be an agreement in literature that $A e$. aegypti was introduced into the Philippines approaching the end of 19th century and followed by the proliferation of this dengue vector [87]. However, there are only two known studies evaluating the insecticide resistance of Ae. aegypti to pyrethroids in the Philippines. In the first study, Ae. aegypti from Luzon Island, Manila was confirmed to be susceptible to dieldrin even after eight years of insecticide application in the country since 1959 [88]. Currently, the latest susceptibility test of Ae. aegypti with the use of pyrethroid was completed in 1997 in Cebu city. It was proven that treatment of curtains with permethrin was an effective vector control measure [89]. These preliminary studies facilitated in verifying the development of resistant strains in the country but the information may not be up to date, and related studies are recommended in the future because DF is endemic in neighboring countries like Malaysia. Susceptibility tests of different pyrethroids and related resistance mechanisms should be attempted on different field populations of Ae. aegypti in the country to confirm insecticide susceptibility status and guarantee the representativeness of the information generated since those insecticides have been put to use for several decades.

\section{Singapore}

It is clear that Ae. aegypti mosquitoes are the primary vectors of DF in Singapore, with the first dengue case reports in the 1960s [90]. In the 1970s, pyrethroids were first introduced to the country to deprive the populations but permethrin resistance was identified in field Ae. aegypti later [91]. Subsequently, an assessment in 1999 revealed a 12.9 -fold of $\mathrm{RR}_{50}$ of field Ae. aegypti against permethrin [13]. Resistance of Ae. aegypti to cypermethrin was also reported in a study between 2004-2007 [92]. More recently, the detection of resistance of Ae. aegypti to pyrethroids were further verified by two comprehensive nationwide insecticide resistance studies on larvae tested with permethrin and etofenprox, as well as adults with cypermethrin, deltamethrin and etofenprox $[14,15]$. Despite the a few decades of gap between these studies, high resistance to pyrethroids remained to persist in the Singaporean Ae. aegypti populations and they continued to thrive, portraying the widespread or probably inappropriate use of pyrethroids ever since they were first introduced in Singapore. The use of synergists (piperonyl butoxide, $S, S, S$,-tributyl phosphorotrithioate, and triphenyl phosphate) was also deemed to be insignificant to the insecticides used in these studies to increase toxicity, signifying negligible roles of metabolic-based resistance when further biochemical investigation discovered that detoxifying enzymes such as monooxygenases, esterases, and GSTs failed to contribute to pyrethroid resistance $[14,15]$. The ineffectiveness of synergists proposes that molecular work is recommended to further investigate the mechanisms contribute to the high pyrethroid resistance exhibited in local Ae. aegypti.

Other than fogging, space spraying, chemical treatment and source reduction as dengue vector control methods, deltamethrin-treated net is an alternative. However, its efficacy was proven to be unsatisfactory against field Ae. aegypti in a recent study [93]. Three molecular investigations have evaluated the roles of individual and multiple Vssc gene mutations in contributing to the developed pyrethroid resistance in Singaporean Ae. aegypti: F1534C, S989P+V1016G and F1534C +V1016G [25, 93, 94]. However, in-depth study showed that G1016 alleles independently pay more responsibility to VSSC gene insensitivity than $\mathrm{C} 1534$ alleles independently $[25,94]$. To the best of our knowledge, S989P +V1016G+F1534C triple mutations in Vssc gene exhibited in the local Ae. aegypti were first reported in Singapore. They exerted the largest pressure in channel sensitivity to permethrin and deltamathrin by 1100 -fold and 90-fold [94], implying the likelihood of reduced efficacy to pyrethroid insecticides. There is also a need of an immediate attention to monitor the occurrence of triple mutations in Vssc gene of field Ae. aegypti populations worldwide, so that the challenge of mosquito vector control will not further exacerbated. The significance of $\mathrm{P} 450$-mediated resistance is mirrored by the highlyresistant Ae. aegypti Singapore (SP) strain, showing 1,650-fold of resistant to permethrin and $\mathrm{PBO}$ has reduced the resistance by 48-fold [25]. P450 genes (CYP4C50, 6BB2, 6F2, 6F3, 6Z7, 6Z8, 9M4, 9M5 and 9M6) were also discovered to be overexpressed in adult females and males [25]. Precise and reliable molecular diagnosis approach to identify metabolic enzymes conferring pyrethroid resistance in Ae. aegypti populations should be emphasized to elucidate the contribution degree of P450 genes to field-resistant strains from distinct areas.

\section{Thailand}

Thailand is the country with the most studies evaluating on the insecticide resistance of pyrethroids to Aedes aegypti in Southeast Asia, reflecting a substantial geographical bias as this species is widespread in many 
countries in this sub-region. Thailand first experienced outbreaks of dengue hemorrhagic fever in 1958 and the disease has since then distributed nationwide [95]. To date, DF or DHF remain a severe health threat in Thailand regardless of unrelenting vigilance in vector control programmes. Reliance has been on the carbamate, organochlorine and organophosphate insecticides since 1950 [17] and the use of synthetic pyrethroids then dominated the market since 1992. Pyrethroid-based formulations with 12 distinct active ingredients are commercially available to all household levels countrywide to control mosquitoes in response to their low price, quick knockdown effect and are relatively safe for human contact because of low mammalian toxicity [17]. Years of routine contact with these insecticides have induced high levels of resistance in Ae. aegypti.

To understand the insecticide susceptibility profile of Thai Ae. aegypti to pyrethroids, there have been several published pioneering works available, but specific geographical restrictions were observed whereby they were conducted in small confined areas during previous decades. Increasing tolerance or resistance to different types of pyrethroids, namely deltamethrin, permethrin, dieldrin, bioallethrin, bioresmethrin or alphacypermethrin, has been reported in larval and adult Ae. aegypti in Thailand [16-18, 96-101]. The absence of large scale evidence-based understanding of the knowledge between the susceptibility profile and insecticides used may largely hinder the effect of dengue control efforts. A comprehensive study evaluating the insecticide susceptibility level will aid in better efficiency in programmeplanning to target the disease vector. More recently published data on pyrethroid resistance in Thai Ae. aegypti addressed the issue that all 32 strains of Ae. aegypti were discovered to be resistant to permethrin, ranging between $4.0-56.4 \%$ [102]. The frequency of susceptibility to deltamethrin in this species showed more than $98 \%$ of mortality to deltamethrin in the majority of the populations, with incipient resistance detected in minor populations. Conversely, all 32 strains of Ae. aegypti were entirely susceptible to lambda-cyhalothrin with $100 \%$ mortality. Significantly high levels of permethrin resistance were documented by [18] (5\% mortality) and [96] (2-9\% mortality) which contrast with this particular study. This may attribute to the differences in sampling sites and the alterations in levels of exposure to permethrin.

Personal protection tools, for instance mosquito coils, are extensively used in Thailand but these products have never been thoroughly studied. Although literature presents on the efficacies of commercially available mosquito coils, up to now, information about detailed assessment on these coils to field populations of $A e$. aegypti remains to be sparse. These studies are irrefutably important when mosquito coils are the top choice of household insecticide formulations worldwide other than aerosols, vaporizing mats and liquid vaporizers. The first report was completed in 2008 in Thailand, showing a phenomenon of tolerance of Ae. aegypti to dl, dT80-allethrin, d, d-T-prallethrin and methoxymethyl-tetrafluorobenzyl tetramethyl-cyclopropanecarboxylate (K3050) under semi-field condition [103]. A similar study was conducted with a total of four field strains of $A e$. aegypti tested against the same active ingredients, employing $25 \mathrm{~m}^{3}$ semi-field test system, topical application test and field efficacy test [104]. Most of the strains were recorded to be tolerant to the mosquito coils tested but pyrethroid resistance may have already developed since noticeably large gaps were observed between the timeframe of sample collection and the course of the study, with up to 31 years gap. It is recommended that, when possible, mosquito test populations should be acquired with shorter gap to prevent bias in the outcomes. The latest related study was accomplished in 2009 using $25 \mathrm{~m}^{3}$ semi-field test and topical application test, demonstrating extremely low susceptibility to $\mathrm{dl}, \mathrm{d}$-T80-allethrin in some field strains [105] and that they may have already developed resistance now. All three studies yielded similar outcomes with low allethrin susceptibility, but it should be noted that direct comparison of results should be avoided due to different testing approaches used. Standardization of method is needed to avoid significant data deviation from a study to another. The knockdown time may vary in regard to types of method employed, that according to Chadwick [106], results carried out in cylinders, small chambers and large rooms are distinct. Moreover, associated assessments on the efficacy of mosquito coil to Thai Ae. aegypti are also needed.

A simple colorimetric assay based on Heated Oligonucleotide Ligation Assay (HOLA) $k d r$ assay from past studies was developed to detect substitutions within domain II, subunit 6. i.e. Met1011, Val1011, Ile1016, and Gly1016 [40]. The V1016G mutation was evidently detected in high allele frequency of 0.23 throughout Thailand in pyrethroid-resistant Ae. aegypti, and that the I1011V mutation to be the minority with an allele frequency of 0.14 [40]. Despite only a thermal cycler being involved in this assay, extra reagents are needed which contributes to the increment of cost. An allele-specific polymerase chain reaction (AS-PCR) assay was then developed to detect the V1016G mutation which was shown to be reliable [107]. Homozygous 1016G mosquitoes were found to be common in Thailand and showed higher survival rates than either heterozygous or wildtype (1016V) mosquitoes upon deltamethrin exposure, indicating this particular mutation confidently related to deltamethrin resistance. Subsequently, the F1534C mutation was discovered as a novel amino acid mutation in 
2010 in permethrin-resistant Ae aegypti, and was reported to play a significant role in contributing permethrin resistance in multiple field strains [108]. The wide distribution of this mutation led to the development of high-throughput molecular tools, namely TaqMan single nucleotide polymorphism (SNP) genotyping and an ASPCR assay, which proved to be consistent in detecting the F1534C resistance mutation in the permethrinresistance Ae. aegypti populations [108]. Recently, a multiplex polymerase chain reaction (PCR) was developed to detect both V1016G and F1534C $k d r$ mutations in Ae aegypti through a single-reaction protocol [61]. This method was evidenced to depict high sensitivity and specificity in detecting the aforesaid $k d r$ mutations, enabling the monitoring of the frequency of mutant alleles across dengue-endemic countries at ease with reduced time and cost.

Other than the discovery of singly-occurred mutations, the novel co-occurrence of the S989P mutation and the V1016G mutation were detected in Thai deltamethrinresistant Ae. aegypti [42]. The 1016G mutation usually coexists with 989P mutation but there is also an absence of 989P mutation in some Thai populations which were homozygous for 1016G [37]. Since some studies showed that the V1016G mutation has been reported in the absence of the S989P mutation, it is likely to hypothesize that this point mutation acts as an additive mutation [42]. Furthermore, the V1016G/F1534C/S989P mutations have been confirmed in Thailand, demonstrating an additive effect on deltamethrin sensitivity which gives high level of resistance [109]. Recent work has also emphasized that the variations of point mutations exerted on pyrethroid-resistant Ae. aegypti revealed different response to insecticides. Thermal fogging spray with deltamethrin and PBO synergist killed all resistant genotypic mosquitoes in indoors [110]. In contrast, the outdoor spray displayed minor impact on the G1016 homozygous mosquitoes, partially killed the G1016/C1534 double heterozygous mosquitoes and triggered high mortality in the C1534 homozygous mosquitoes [110]. Further associated studies should be conducted to understand other polymorphisms complementing the Vssc mutation and how they are related to the resistance phenotype when selection pressure is extrapolated to act on the survival of pyrethroid-resistant Ae. aegypti. Moreover, further verification is also needed to make implications that the aforesaid mutations are linked to deltamethrin resistance. Other than the target site insensitivity mechanism acts upon the pyrethroid resistance in Ae. aegypti, a previous study addressed the absence of the 1016G mutation in deltamethrin resistance mosquito strains and revealed the role of mixed function oxidases in conferring the resistance [16]. Thus, the contributions of metabolic mechanisms in these wild-type individuals upon deltamethrin exposure earn further attentions. This overlaps the study of Somwang et al. [111], which described oxidative enzyme systems also involve in pyrethroid resistance in Ae. aegypti in Thailand. Another study showed that biochemical assays are very much required when a difference of low $k d r$ resistant allele frequency of S989P and V1016G with high level of permethrin resistance was reported in field strains of Ae. aegypti, which this implies detoxification enzymes show the possibility to be involved in insecticide resistance mechanisms [112].

Biochemical assays used to detect enzymes metabolizing insecticides have been available for over three decades to monitor insecticide resistance of Ae. aegypti in various countries. In Thailand, the first related study was accomplished in 2002 using laboratory bred artificially selected resistant Ae. aegypti. GST and esterase activities were detected to be only marginally higher relative to the susceptible strain, signifying that both enzyme groups show no major role in permethrin resistance [113]. In contrast, the subsequent biochemical assay of metabolic enzymes tested with field Ae. aegypti to pyrethroid resistance revealed esterase, monooxygenase and GST are closely associated with permethrin resistance whereas deltamethrin resistance is related to esterase and monooxygenase [21]. Later, a number of studies proposed that an elevated level of mixed function oxidase was usually in association with pyrethroid resistance $[16,114]$. Moreover, considerable escalated levels of esterases and GSTs were stated in some field strains of pyrethroid-resistant Ae. aegypti [114]. The latest study demonstrated that the aforementioned enzymes were either unrelated or merely contributed partially in pyrethroid resistance [115]. In regards to the discrepancies of these enzymes as contributory factors to pyrethroid resistance in Ae. aegypti, it should be noted that in vitro experiments may not reflect the in vivo circumstances of insect metabolizing insecticide molecules and thus, field studies including numerous variables should be considered in the future.

\section{Timor-Leste}

Timor-Leste is not excluded from vector-borne diseases transmitted by Aedes mosquitoes, due to its generally warm and humid climate which is conducive for their growth. Dengue cases were first reported in 2003, followed by an outbreak resulted in 933 cases and 37 deaths in 2005 in Dili, Bobonaro and Baucau [116, 117]. Although Ae. aegypti was extensively spread in the country [116], there was only single international project carried out, by Frances et al. [118] who employed bottle bioassay to examine insecticide resistance in Ae. aegypti and the respective biochemical mechanisms using pyrethroids (permethrin, resmethrin, lambda-cyhalothrin). 
These insecticides were in line with the other insecticides used more than a decade ago for vector control programmes in the country as stated by Whelan \& Petitt [117]. Since pyrethroid resistance was detected in Ae. aegypti collected from a single site in Dili with elevated levels of esterases, there is a need in investigating the efficacies and mechanisms contributed to the resistance of pyrethroids towards the Ae. aegypti populations in Timor-Leste.

\section{Vietnam}

DHF was first documented in Hanoi, Vietnam in 1958 [119], followed by the first and second outbreaks recorded in 1960 and 1963, respectively, in South Vietnam [120]. Vietnam, like all the other Southeast Asian countries, utilizes chemical insecticides as the primary tool in ceasing spread of the vector of DHF, Ae. aegypti. Although Ae. aegypti was introduced to the country in 1915 [121] and DHF has been reported to be endemic in Vietnam for decades [122], there are insufficient amount of studies available in evaluating the efficacies of pyrethroids to Ae. aegypti and their related mechanisms [41, 122-126].

The first insecticide resistance study of Ae. aegypti was conducted in 1998 and 1999, showing that the mosquitoes were resistant to few pyrethroid insecticides in several locations of Central Highlands and Nam Bo [122]. Later, a similar but more comprehensive study was completed in 2004, encompassing four regions of Vietnam, and revealed that Ae. aegypti from numerous locations in the Centre and North regions were susceptible to pyrethroids but those from South and Central Highlands were more resistant [124]. This was believed to be related to the frequent and prolonged use of pyrethroids in the highlands for the Ae. aegypti control programme [124]. Apart from the aforementioned factor that may influence the susceptibility status of Ae. aegypti to pyrethroids, mosquitoes from places with high populations develop higher resistance than those from outskirts; $\mathrm{Hu}-$ ber et al. [123] showed that Ae. aegypti in cities with high populations, like Ho Chi Minh City, developed higher resistance than those from the outskirts or Long An Province. Other than inspecting previously reported dengue hotspots, these pioneer studies provided insights into pyrethroid resistance in Ae. aegypti and reported that Ae. aegypti populations in the country had already developed resistance to some pyrethroids.

The most extensive nationwide assessment of pyrethroid resistance in Ae. aegypti was completed in 2009, approximately a century after this disease vector made its way to Vietnam. A total of 527 collection points were involved from northern to southern Vietnam [125]. A simple bioassay of fourth instar larvae using glass vials was developed to detect knockdown susceptibility [125]. The most notable outcome of this study demonstrated a pronounced increment of resistance in Ae. aegypti to dallethrin with decrease in the latitude of sampling sites [125], corresponding to the findings of an earlier study [124]. Analysis of point mutations was further investigated and the F1534C mutation was verified to be the chief point mutation that gave rise to high resistance in the specimens collected from the South, whereas the heterozygous V1016G mutation was very low in frequency [126]. Although low frequencies were detected in the North and the percentage of homozygous F1534C remained low (7.4\%), unrestrained use of photo-stable pyrethroids that persists in the environment may induce selection pressure for this point mutation, which will result in more resistance offspring. With 21,000 liters of pyrethroids used in dengue control operations in 20 southern provinces in 2007 [127], it is no surprise that Ae. aegypti populations from Vietnam have developed insecticide resistance. Therefore, the use of $\mathrm{PBO}$ as a synergist was considered to increase the efficacy of detalmethrin to Ae. aegypti from Nha Trang [41]. The study subsequently proved that synergists might play crucial role in Ae. aegypti control programme [41]. Moreover, Nha Trang strain housed multiple resistance, the overexpressed $\mathrm{P} 450$ gene CYP9J32 relative to the susceptible strain was found capable in metabolizing deltamethrin effectively, as well as two homozygous $k d r$ mutations which were the I1011V (100\%) mutation and the V1016I (67\%) mutation. Attention should be paid to the detection of the V1016I mutation in Vietnam when this point mutation was only circumscribed in the continent of America in the past $[38,45,128]$. Thus, consistent monitoring of insecticide resistance is required.

\section{Future challenges and perspectives}

When development of resistance has become a worldwide issue, there are alternatives to control Ae. aegypti. Environmental control in Southeast Asia involves source reduction and the use of mosquito traps or screen net covers [129-132]. Standing water and unnecessary containers, in both indoor and outdoor conditions, should be eliminated to prevent breeding of mosquitoes, specifically Ae. aegypti and other container breeders [79]. Containers that performed functions in daily life should be screened or properly covered. Source reduction should also include getting rid of natural habitats that collect water, such as bamboo stumps and tree holes to avoid the breeding of Ae. aegypti.

To diversify the choices of vector control, research has been reinforced in developing pathogenic organisms to combat dengue vector. In biological control, natural enemies are either predators, microbes or parasites [79]. Examples of biological control in Southeast Asia include the participation of predaceous aquatic insects as natural enemies to suppress mosquito populations by predating 
on mosquito larvae as food source $[57,133,134]$ or the use of the entomopathogenic bacteria Bacillus thuringiensis var. israelensis to destroy the gut lining of mosquito larvae [130, 135]. Hypothetically, predaceous animal species should result in reduction of mosquito populations, but there is limited evidence regarding tangible proof of related declining disease burdens. Therefore, it should be noted that these methods would work well alongside chemical insecticides but should never be employed as a sole control tactic during epidemic outbreaks of dengue when immediate elimination of disease vectors should be prioritized.

Another biological control method involves the release of Ae. aegypti infected with Wolbachia. These naturallyoccurring bacteria infect a wide range of arthropods and nematodes but are absent in Ae. aegypti [136]. To decrease dengue transmission, Wolbachia from naturally infected organisms are vertically transmitted into $A e$. aegypti. This causes sterility via cytoplasmic incompatibility, resulting in eggs without progeny when an uninfected female Ae. aegypti mates with a Wolbachiainfected male [137]. Wolbachia has drawn much attention and field trials are ongoing in several countries such as Australia [138], Vietnam [139] and Indonesia [140]. Despite wMel Wolbachia showing positive result in lowering the incidence of dengue in human populations in northern Australia [138], wMelPop Wolbachia with even more significant resistance to DENV infection failed to establish successfully in Australia and Vietnam. Hence, more progressive studies pertaining to the large-scale field release of Wolbachia-infected Ae. aegypti are essential before this approach would show success in dengue control programmes throughout dengue-endemic countries.

It is irrefutable that chemical insecticides remain the primary vector-control intervention, specifically during an emergency epidemic. When Ae. aegypti exhibited a propensity to develop resistance to countless groups of chemical insecticides leading to loss of functions, insect growth regulators (IGRs) may likely reduce resistance developing. The discovery of IGRs is in accordance with the knowledge of their growth, development, function and behavior. Thus, the use of IGRs has the likelihood to conquer the market of many other insecticides, and Lau et al. [141] reported that this group of insecticides poses encouraging results to control the field populations of Ae. aegypti, specifically cyromazine.

Pyrethroid resistance in Southeast Asian Ae. aegypti should not be overlooked. Many countries rely on the interventions of chemical insecticides to control the mosquito vectors of dengue. In this review of literature, several issues that highlight the need for immediate attention are addressed. Undeniably, these studies demonstrated a strong tendency of lopsided geographical distribution in published reports with more than half published from Thailand, Indonesia and Malaysia. Although studies retrieved from the database reflected the burden of DF, it is believed that some dengue-endemic countries such as Vietnam and Myanmar may have restricted the accessibility of the database without releasing to the public. This leads to difficulty in deciding on suitable insecticides for dengue control and, therefore, a platform with insecticide resistance status of different Ae. aegypti populations in a homogenous format would critically solve related challenges and ease future vector control planning. In certain cases, uniformity of protocols was neglected. Examining the broad range in the methodologies utilized to record and analyze resistance or susceptibility data of various studies is very challenging. Thus, only some attempts were made to specify the level of susceptibility that the standardization of methods in all of the studies would contribute to reliable comparison of the outcomes. Method of recording insecticide resistance should be consistent, taking $\mathrm{LC}_{50} /$ $\mathrm{LT}_{50} / \mathrm{KT}_{50}$ or other similar set of data for instance, though actual values may still have to be provided for comparison in some circumstances.

In addition, the use of the revised version of World Health Organization (WHO) guidelines was not practiced in all the studies. WHO has initially published two different databases on the diagnostic dosages of distinct insecticides [142, 143]; there are still some studies that employed the original diagnostic doses to examine the susceptibility status of Ae. aegypti $[8,13,18]$, while some have already opted for the newly revised guideline $[97,99]$. In recent times, WHO has released the latest version of test procedures to detect insecticide resistance for both Aedes larvae and adults [144]. All researchers are recommended to adhere to the changes made by WHO on the guidelines to evaluate the resistance status of field Aedes population. Furthermore, future studies should pinpoint on widening the number of sampling sites on a wide array of active ingredients of the pyrethroid group that are yet to be tested in most cases, including resmethrin, bifenthrin, flumethrin and tralomethrin. These may have potential in effective control of Ae. aegypti or cross-resistance within the active ingredients of the pyrethroid group that may have already occurred whereby the last resort would be abandoning of the pyrethroid group of insecticides. The prevalent use of pyrethroid-based mosquito coils calls for further validation on their efficacies across Southeast Asia. As of now, little has been reported on the efficacies of these mosquito coils to Ae aegypti populations.

Efforts of understanding the aforementioned mechanisms on Ae. aegypti are urgently required, especially in some dengue-endemic countries with unavailability of associated reports, as vector control against Ae. aegypti 
continues to be the corner stone in preventing dengue transmission and outbreak control. Bioassays are only capable in detecting resistance that has already existed in a strain, while diagnostic assays can detect resistance once it appears that this may avoid the failure in vector management. $K d r$ assays have long been used for detecting point mutations to observe the effect of control tactics on insecticide resistance, but it is crucial to note that these molecular assays of target site resistance should also not replace bioassays until other resistance mechanisms, e.g. metabolic resistance can be complemented by comparable assays. A major advantage of the molecular approach is that sequencing of Ae. aegypti genome aids in progressive study on insecticide resistance mechanisms and further research should focus on searching for new diagnostic markers of pyrethroid resistance in dengue vectors. Biochemical assays in detecting enzymes linked to pyrethroid resistance have been utilized in several Southeast Asian countries, because these assays deliver important information for estimating resistance. However, the short of specificity and sensitivity of some assays may lead to complications in analyzing data. As for the addition of synergists, such as PBO used to examine the significant of metabolic resistance, the protocol can be very problematic as a huge amount of alive Ae. aegypti populations will be needed. Hence, the above-mentioned challenge in biochemical assays are more difficult when analyzing the use of synergist data.

\section{Conclusions}

Across Southeast Asia, dengue appears to be endemic. Thus far, the unavailability of data regarding pyrethroid resistance in Ae. aegypti in some parts of Southeast Asia, such as Brunei Darussalam, Christmas Island of Australia and The Andaman/Nicobar Islands of India, necessitates immediate research to be conducted. As for the reported countries, resistance status of many Ae. aegypti populations to pyrethroids demonstrates the need for more effective control strategies, possibly the intervention of new insecticides. The fact that either migration or de novo mutations is creating issue regarding the spread of $k d r$ mutations that were once occurred locally are now discovered in different continents, despite geographical separations, should be highlighted. More efforts are bound to combat insecticide resistance to stop the spread of diseases and vectors. However, it is understandable that this could be a difficult undertaking, because a substantial amount of funds is needed. Therefore, vector control success will very much count on policymakers, academics and scientists.

\section{Abbreviations}

AS-PCR: Allele-specific polymerase chain reaction; DENV: Denque virus: DF: Dengue fever; DHF: Dengue hemorrhagic fever; GST: Glutathione
S-transferases; IGR: Insect growth regulator; kdr: Knockdown resistance; PBO: Piperonyl butoxide; PCR: Polymerase chain reaction; SNP: Single nucleotide polymorphism; Vssc: Voltage-sensitive sodium channel; WHO: World Health Organization

\section{Author details}

${ }^{1}$ Tropical Infectious Diseases Research \& Education Centre (TIDREC), University of Malaya, 50603 Kuala Lumpur, Malaysia. ${ }^{2}$ Institute of Biological Sciences, Faculty of Science, University of Malaya, 50603 Kuala Lumpur, Malaysia.

\section{Funding}

This study was funded by University of Malaya research grant (RP021D16SUS).

\section{Authors' contributions}

CDC, MSA and VLL conceived the study. ZHAY conducted the review and drafted the manuscript. ZHAY and VLL wrote the final version of the manuscript. All authors read and approved the final manuscript.

Ethics approval and consent to participate

Not applicable.

\section{Competing interests}

The authors declare that they have no competing interests.

\section{Publisher's Note}

Springer Nature remains neutral with regard to jurisdictional claims in published maps and institutional affiliations.

\section{Author details}

${ }^{1}$ Tropical Infectious Diseases Research \& Education Centre (TIDREC), University of Malaya, 50603 Kuala Lumpur, Malaysia. ${ }^{2}$ Institute of Biological Sciences, Faculty of Science, University of Malaya, 50603 Kuala Lumpur, Malaysia.

Received: 7 March 2018 Accepted: 14 May 2018

Published online: 04 June 2018

\section{References}

1. World Health Organization. Dengue and severe dengue. 2017. http://www. who.int/mediacentre/factsheets/fs117/en/. Accessed 20 Jan 2018.

2. Bisset JA, Rodríguez MM, San Martín JL, Romero JE, Montoya R. Evaluación de la resistencia a insecticidas de una cepa de Aedes aegypti de El Salvador. Pan Am J Public Health. 2009;26:229-34.

3. Housset P, Dickmann R. A promise fulfilled-pyrethroid development and the benefits for agriculture and human health. Bayer Cropscience. 2009; 62:135-44.

4. Scott JG. Pyrethroid insecticides. ISI Atlas Sci Pharmacol. 1988;2:125-8.

5. Narahashi T. Nerve membrane ion channels as the target site of insecticides. Mini Rev Med Chem. 2002;2:419-32.

6. Smith LB, Kasai S, Scott JG. Pyrethroid resistance in Aedes aegypti and Aedes albopictus: Important mosquito vectors of human diseases. Pestic Biochem Phys. 2016;133:1-12.

7. Wan-Norafikah O, Nazni WA, Lee HL, Zainol-Ariffin P, Sofian-Azirun M. Permethrin resistance in Aedes aegypti (Linnaeus) collected from Kuala Lumpur. Malaysia. J Asia Pac Entomol. 2010;13:175-82.

8. Loke SR, Tan AWA, Ahmad NW, Lee HL, Sofian-Azirun M. Insecticide susceptibility status of field-collected Aedes (Stegomyia) aegypti (L.) at a dengue endemic site in Shah Alam, Selangor, Malaysia. Southeast Asian J Trop Med Pub Health. 2012;43:34-47.

9. Ishak IH, Jaal Z, Ranson H, Wondji CS. Contrasting patterns of insecticide resistance and knockdown resistance $(k d r)$ in the dengue vectors Aedes aegypti and Aedes albopictus from Malaysia. Parasit Vectors. 2015;8:181.

10. Wuliandari JR, Lee SF, White VL, Tantowijoyo W, Hoffmann AA, EndersbyHarshman NM. Association between three mutations, F1565C, V1023G and S996P, in the voltage-sensitive sodium channel gene and knockdown resistance in Aedes aegypti from Yogyakarta, Indonesia. Insects. 2015;6:65885.

11. Astari S, Ahmad I. Insecticide resistance and effect of piperonyl butoxide as a synergist in three strains of Aedes aegypti (Linn.) (Diptera: Culicidae) 
against insecticides permethrin, cypermethrin, and d-allethrin. Bul Penelitian Kesehatan. 2005;33:73-9.

12. Ahmad I, Astari S, Tan M. Resistance of Aedes aegypti (Diptera: Culicidae) in 2006 to pyrethroid insecticides. Pak J Biol Sci. 2007;10:3688-92.

13. Lai TP, Yatiman R, Lam-Phua SG. Susceptibility of adult field strains of Aedes aegypti and Aedes albopictus in Singapore to pirimiphos-methyl and permethrin. J Am Mosq Control Assoc. 2001;17:144-6.

14. Koou SY, Chong CS, Vythilingam I, Lee CY, Ng LC. Insecticide resistance and its underlying mechanisms in field populations of Aedes aegypti adults (Diptera: Culicidae) in Singapore. Parasit Vectors. 2014;7:471.

15. Koou SY, Chong CS, Vythilingam I, Ng LC, Lee CY. Pyrethroid resistance in Aedes aegypti larvae (Diptera: Culicidae) from Singapore. J Med Entomol. 2014;51:170-81.

16. Yaicharoen $R$, Kiatfuengfoo $R$, Chareonviriyaphap $T$, Rongnoparut $P$. Characterization of deltamethrin resistance in field populations of Aedes aegypti in Thailand. J Vector Ecol. 2005;30:144-50.

17. Chareonviriyahpap T, Aum-aung B, Ratanatham S. Current insecticide resistance patterns in mosquito vectors in Thailand. Southeast Asian J Trop Med Pub Health. 1999:30:184-94.

18. Jirakanjanakit $N$, Rongnoparut $P$, Saengtharatip S, Chareonviriyaphap T, Duchon S, Bellec C, et al. Insecticide susceptible/resistance status in Aedes (Stegomyia) aegypti and Aedes (Stegomyia) albopictus (Diptera: Culicidae) in Thailand during 2003-2005. J Econ Entomol. 2007;100:545-50.

19. Brito LP, Linss JG, Lima-Camara TN, Belinato TA, Peixoto AA, Lima JBP, et al. Assessing the effects of Aedes aegypti kdr mutations on pyrethroid resistance and its fitness cost. PLoS One. 2013;8:e60878.

20. Chareonviriyaphap T, Bangs MJ, Suwonkerd W, Kongmee M, Corbel V, Ngoen-Klan R. Review of insecticide resistance and behavioral avoidance of vectors of human diseases in Thailand. Parasit Vectors. 2013;6:280.

21. Paeporn P, Supaphathom K, Sathantriphop S, Chareonviritaphap T, Yaicharoen R. Behavioural responses of deltamethrin-and permethrinresistant strains of Aedes aegypti when exposed to permethrin in an excitorepellency test system. Dengue Bull. 2007;31:153-9.

22. Thanispong K, Achee NL, Grieco JP, Bangs MJ, Suwonkerd W, Prabaripai A, et al. A high throughput screening system for determining the three actions of insecticides against Aedes aegypti (Diptera: Culicidae) populations in Thailand. J Med Entomol. 2010;47:833-41.

23. Grieco JP, Achee NL, Sardelis MR, Chauhan KR, Roberts DR. A novel highthroughput screening system to evaluate the behavioral response of adult mosquitoes to chemicals. J Am Mosq Control Assoc. 2005;21:404-11.

24. Chareonviriyaphap T, Kongmee M, Bangs MJ, Sathantriphop S, Meunworn V, Parbaripai A, et al. Influence of nutritional and physiological status on behavioral responses of Aedes aegypti (Diptera: Culicidae) to deltamethrin and cypermethrin. J Vector Ecol. 2006;31:89-101.

25. Kasai S, Komagata O, Itokawa K, Shono T, Ng LC, Kobayashi M, et al. Mechanisms of pyrethroid resistance in the dengue mosquito vector, Aedes aegypti: target site insensitivity, penetration, and metabolism. PLoS Negl Trop Dis. 2014;8:e2948

26. Nkya TE, Akhouayri I, Kisinza W, David JP. Impact of environment on mosquito response to pyrethroid insecticides: facts, evidences and prospects. Insect Biochem Mol Biol. 2013:43:407-16.

27. Wood OR, Hanrahan S, Coetzee M, Koekemoer LL, Brooke BD. Cuticle thickening associated with pyrethroid resistance in the major malaria vector Anopheles funestus. Parasit Vectors. 2010;3:67.

28. Lee CY, Yap HH. Overview on urban pests: a Malaysian perspective. In: Chong NL, Lee CY, Jaal Z, Yap HH, editors. Urban Pest Control - A Malaysian Perspective. 2nd ed. Penang, Malaysia: Vector Control Research Unit, Universiti Sains Malaysia; 2003.

29. Djouaka RF, Bakare AA, Coulibaly ON, Akogbeto MC, Ranson H, Hemingway J, et al. Expression of the cytochrome P450, CYP6P3 and CYP6M2 are significantly elevated in multiple pyrethroid resistant populations of Anopheles gambiae s.s. from southern Benin and Nigeria. BMC Genomics. 2008:9:538.

30. David JP, Coissac E, Melodelima C, Poupardin R, Riaz MA, Chandor-Proust A, et al. Transcriptome response to pollutants and insecticides in the dengue vector Aedes aegypti using next-generation sequencing technology. BMC Genomics. 2010;11:216.

31. Hemingway J, Ranson $\mathrm{H}$. Insecticide resistance in insect vectors of human disease. Annu Rev Entomol. 2010;45:371-91.

32. Ishak IH, Kamgang B, Ibrahim SS, Riveron JM, Irving H, Wondji CS. Pyrethroid resistance in Malaysian populations of dengue vector Aedes aegypti is mediated by CYP9 family of cytochrome P450 genes. PLoS Negl Trop Dis. 2017;11:e0005302

33. Enayati $A A$, Vatandoost $H$, Ladonni $H$, Townson $H$, Hemingway J. Molecular evidence for a $k d r$-like pyrethroid resistance mechanism in the malaria vector mosquito Anopheles stephensi. Med Vet Entomol. 2003;17:138-44.

34. Martinez-Torres D, Chevillon C, Brun-Barale A, Bergé JB, Pasteur N, Pauron D. Voltage-dependent $\mathrm{Na}+$ channels in pyrethroid-resistant Culex pipiens $\mathrm{L}$ mosquitoes. Pest Manag Sci. 1999;55:1012-20.

35. Xu Q, Liu H, Zhang L, Liu N. Resistance in the mosquito, Culex quinquefasciatus, and possible mechanisms for resistance. Pest Manag Sci. 2005;61:1096-102.

36. Verhaeghen K, Van Bortel W, Trung HD, Sochantha T, Keokenchanh K, Coosemans M. Knockdown resistance in Anopheles vagus, An. sinensis, An. paraliae and An. peditaeniatus populations of the Mekong region. Parasit Vectors. 2010;3:59.

37. Brengues C, Hawkes NJ, Chandre F, McCarroll L, Duchon S, Guillet P, et al. Pyrethroid and DDT cross-resistance in Aedes aegypti is correlated with novel mutations in the voltage-gated sodium channel gene. Med Vet Entomol. 2003;17:87-94.

38. Saavedra-Rodriguez K, Urdaneta-Marquez L, Rajatileka S, Moulton M, Flores $A E$, Fernandez-Salas I, et al. A mutation in the voltage-gated sodium channel gene associated with pyrethroid resistance in Latin American Aedes aegypti. Insect Mol Biol. 2007;16:785-98.

39. Kawada H, Oo SZM, Thaung S, Kawashima E, Maung YNM, Thu HM, et al. Co-occurrence of point mutations in the voltage-gated sodium channel of pyrethroid-resistant Aedes aegypti populations in Myanmar. PLoS Negl Trop Dis. 2014;8:e3032

40. Rajatileka S, Black WC 4th, Saavedra-Rodriguez K, Trongtokit Y, Apiwathnasorn C, McCall PJ, et al. Development and application of a simple colorimetric assay reveals widespread distribution of sodium channel mutations in Thai populations of Aedes aegypti. Acta Trop. 2008;108:54-7.

41. Bingham G, Strode C, Tran L, Khoa PT, Jamet HP. Can piperonyl butoxide enhance the efficacy of pyrethroids against pyrethroid-resistant Aedes aegypti? Trop Med Int Health. 2011;16:492-500.

42. Srisawat $R$, Komalamisra $N$, Eshita $Y$, Zheng $M$, Ono $K$, Itoh TQ, et al. Point mutations in domain II of the voltage-gated sodium channel gene in deltamethrin-resistant Aedes aegypti (Diptera: Culicidae). Appl Entomol Zool. 2010;45:27582

43. Marcombe S, Sutherland I, Brey P. Vector mapping, characterization of insecticide resistance of Aedes populations, and entomology capacity development in Lao PDR. 2017. http://www.pasteur.la/project-carried-on-inthe-lab-8/vector-mapping-characterization-of-insecticide-resistance-of-aedespopulations-and-entomology-capacity-development-in-lao-pdr/. Accessed 23 Dec 2017.

44. Hamid PH, Prastowo J, Ghiffari A, Taubert A, Hermosilla C. Aedes aegypti resistance development to commonly used insecticides in Jakarta. Indonesia. PLoS One. 2017;12:e0189680

45. Alvarez LC, Ponce G, Saavedra-Rodriguez K, Lopez B, Flores AE. Frequency of V1016I and F1534C mutations in the voltage-gated sodium channel gene in Aedes aegypti in Venezuela. Pest Manag Sci. 2015;71:863-9.

46. Linss JGB, Brito LP, Garcia GA, Araki AS, Bruno RV, Lima JBP, et al. Distribution and dissemination of the Val1016lle and Phe1534Cys $k d r$ mutations in Aedes aegypti Brazilian natural populations. Parasit Vectors. 2014:7:25

47. Dolabella SS, Santos RLC, Silva MCN, Steffler LM, Ribolla PEM, Cavalcanti $\mathrm{SCH}$, et al. Detection and distribution of $\mathrm{V} 1016 \mathrm{kdr}$ mutation in the voltagegated sodium channel gene in Aedes aegypti (Diptera: Culicidae) populations from Sergipe State. Northeast Brazil. J Med Entomol. 2016;53: 967-71.

48. Kawada H, Higa Y, Futami K, Muranami Y, Kawashima E, Osei JH, et al. Discovery of point mutations in the voltage-gated sodium channel from African Aedes aegypti populations: potential phylogenetic reasons for gene introgression. PLoS Negl Trop Dis. 2016;10:e0004780.

49. Strode C, Wondji CS, David JP, Hawkes NJ, Lumjuan N, Nelson DR, et al. Genomic analysis of detoxification genes in the mosquito Aedes aegypti. Insect Biochem Mol Biol. 2008;38:113-23.

50. Feyereisen R. Insect P450 enzymes. Annu Rev Entomol. 1999;44:507-33.

51. Zhu F, Feng JN, Zhang L, Liu N. Characterization of two novel cytochrome P450 genes in insecticide-resistant house-flies. Insect Mol Biol. 2008;17:27-37. 
52. Marcombe S, Poupardin R, Darriet F, Reynaud S, Bonnet J, Strode C, et al. Exploring the molecular basis of insecticide resistance in the dengue vector Aedes aegypti: a case study in Martinique Island (French West Indies). BMC Genomics. 2009:10:494

53. Stevenson BJ, Pignatelli P, Nikou D, Paine MJ. Pinpointing P450 associated with pyrethroid metabolism in the dengue vector, Aedes aegypti: developing new tools to combat insecticide resistance. PLoS Negl Trop Dis. 2012;6:e1595.

54. Pavlidi N, Monastirioti M, Daborn P, Livadaras I, Van Leeuwen T, Vontas J. Transgenic expression of the Aedes aegypti CYP9J28 confers pyrethroid resistance in Drosophila melanogaster. Pestic Biochem Phys. 2012;104:132-5.

55. Lumjuan N, McCarroll L, Prapanthadara LA, Hemingway J, Ranson H. Elevated activity of an Epsilon class glutathione transferase confers DDT resistance in the dengue vector, Aedes aegypti. Insect Biochem Mol Biol. 2005;35:861-71.

56. Lumjuan N, Stevenson BJ, Prapanthadara LA, Somboon P, Brophy PM, Loftus $B J$, et al. The Aedes aegypti glutathione transferase family. Insect Biochem Mol Biol. 2007;37:1026-35.

57. Seng CM, Setha T, Nealon J, Chantha N, Socheat D, Nathan MB. The effect of long-lasting insecticidal water container covers on field populations of Aedes aegypti (L.) mosquitoes in Cambodia. J Vector Ecol. 2008;33:333-41.

58. Polson KA, Curtis C, Seng CM, Olson JG, Chantha N, Rawlins SC. Susceptibility of two Cambodian population of Aedes aegypti mosquito larvae to temephos during 2001. Dengue Bull. 2001;25:79-83.

59. Boyer S, Lopes S. WHOPES methods to test insecticide susceptibility of 4 Aedes aegypti field populations in Cambodia. Dengue integrated vector management: dissemination and policy uptake workshop: Phnom Penh; December 2016.

60. Yanola J, Somboon P, Walton C, Nachaiwieng W, Somwang P, Prapanthadara LA. High-throughput assays for detection of the F1534C mutation in the voltage-gated sodium channel gene in permethrin-resistant Aedes aegypti and the distribution of this mutation throughout Thailand Trop Med Int Health. 2011;16:501-9.

61. Saingamsook J, Saeung A, Yanola J, Lumjuan N, Walton C, Somboon P. A multiplex PCR for detection of knockdown resistance mutations, V1016G and F1534C, in pyrethroid-resistant Aedes aegypti. Parasit Vectors. 2017;10:465.

62. Ministry of Health Republic of Indonesia. Demam Berdarah Biasanya Mulai Meningkat di Januari. 2015. http://www.depkes.go.id/article/view/ 15011700003/demam-berdarah-biasanya-mulai-meningkat-di-januari.html. Accessed 4 Dec 2017.

63. Sayono S, Hidayati APN, Fahri S, Sumanto D, Dharmana E, Hadisaputro S, et al. Distribution of voltage-gated sodium channel (Nav) alleles among the Aedes aegypti populations in central Java province and its association with resistance to pyrethroid insecticides. PLoS One. 2016;11:e0150577.

64. Astuti EP, Ipa M, Pradani FY. Resistance detection of Aedes aegypti larvae to cypermethrin from endemic area in Cimahi City West Java. J Vector Borne Dis. 2014:6:7-12.

65. Nazni WA, Lee HL, Azahari AH. Adult and larval insecticide susceptibility status of Culex quinquefasciatus (Say) mosquitoes in Kuala Lumpur Malaysia. Trop Biomed. 2005;22:63-8.

66. Hamid PH, Prastowo J, Widyasari A, Taubert A, Hermosilla C. Knockdown resistance $(k d r)$ of the voltage-gated sodium channel gene of Aedes aegypti population in Denpasar, Bali, Indonesia. Parasit Vectors. 2017;10:283.

67. Tsuda Y, Kobayashi J, Nambanya S, Miyagi I, Toma T, Phompida S, et al. An ecological survey of dengue vector mosquitos in central Lao PDR. Southeast Asian J Trop Med Pub Health. 2002;33:63-7.

68. Jennings CD, Phommasack B, Sourignadeth B, Kay BH. Aedes aegypti control in the Lao People's Democratic Republic, with reference to copepods. Am J Trop Med Hyg. 1995;53:324-30.

69. Hiscox A, Kaye A, Vongphayloth K, Banks I, Piffer M, Khammanithong P, et al. Risk factors for the presence of Aedes aegypti and Aedes albopictus in domestic water-holding containers in areas impacted by the Nam Theun 2 hydroelectric project, Laos. Am J Trop Med Hyg. 2013;8:1070-8.

70. Ministry of Health: Lao People's Democratic Republic. National Strategy for Malaria Control and pre-Elimination, 2011-2015, Lao PDR. 2010. https:// www.thehealthcompass.org/sites/default/files/project_examples/ Lao\%20PDR\%20NMSP\%202011-2015.pdf. Accessed 12 Jan 2018.

71. Low VL, Chen CD, Lee HL, Tan TK, Chen CF, Leong CS, et al. Enzymatic characterization of insecticide resistance mechanisms in field populations of Malaysian Culex quinquefasciatus Say (Diptera: Culicidae). PLoS One. 2013;8: e79928.
72. Ministry of Health Malaysia Situasi semasa deman denggi dan Zika di Malaysia bagi minggu 1/2017 dari 1 hingga 7 Januari 2017. Putrajaya, Malaysia: Kenyataan Akhbar Menteri Kesihatan Malaysia. 2017.http://www. moh.gov.my/index.php/database_stores/store_view_page/21/848. Accessed 15 Jan 2018.

73. Rohani A, Chu WL, Saadiyah I, Lee HL, Phang SM. Insecticide resistance status of Aedes albopictus and Aedes aegypti collected from urban and rural areas in major towns of Malaysia. Trop Biomed. 2001;18:29-39.

74. Lee HL, Chong WL. Glutathion S-transferase activity and DDT-susceptibility of Malaysian mosquitos. Southeast Asian J Trop Med Pub Health. 1999;26:164-7.

75. Hasan HA, Jaal Z, Ranson H, McCall P. Pyrethroid and organophosphate susceptibility status of Aedes aegypti (Linnaeus) and Aedes albopictus (Skuse) in Penang. Malaysia. Int J Entomol Res. 2016;3:91-5.

76. Rosilawati R, Lee HL, Nazni WA, Nurulhusna AH, Roziah A, Asuad MK, et al. Pyrethroid Resistance Status of Aedes (Stegomyia) aegypti (Linneaus) from Dengue Endemic Areas in Peninsular Malaysia. Int Med J Malaysia. 2017;16:2.

77. Hamdan H, Sofian-Azirun M, Nazni WA, Lee HL. Insecticide resistance development in Culex quinquefasciatus (Say), Aedes aegypti (L.) and Aedes albopictus (Skuse) larvae against malathion, permethrin and temephos. Trop Biomed. 2005;22:45-52.

78. Yap HH, Lim MP, Chong NL, Lee CY. Efficacy and sublethal effects of mosquito coils on Aedes aegypti and Culex quinquefasciatus (Diptera: Culicidae). In: Proceedings of the 2 nd International Conference on Insect pests in the urban environment. Edinburgh, Scotland, United Kingdom: Heriot-Watt University; 1996. p. 177-84.

79. Yap HH, Zairi J, Lee YW, Adanan CR. Mosquito Control,. In: Lee CY, Yap HH, Chong NL, Zairi J, editors. Urban pest control, a Malaysian perspective, 2nd edn. Penang, Malaysia: Universiti Sains Malaysia; 2003. p. 43-53.

80. Mulla MS, Thavara U, Tawatsin A, Kong-Ngamsuk W, Chompoosri J. Mosquito burden and impact on the poor: measures and costs for personal protection in some communities in Thailand. J Am Mosq Control Assoc. 2001;17:153-9.

81. World Health Organization. Guidelines for efficacy testing of household insecticide products: Mosquito coils, vaporizer mats, liquid vaporizers, ambient emanators and aerosol control of neglected tropical diseases, WHO pesticide evaluation scheme. 2009. http://apps.who.int/iris/bitstream/10665/ 70071/1/WHO_HTM_NTD_WHOPES_2009.3_eng.pdf. Accessed 15 Jan 2018.

82. El-garj F, Avicor SW, Wajidi MF, Jaal Z. Comparative efficacy of spatial repellents containing $\mathrm{d}$-allethrin and d-trans allethrin against the major dengue vector Aedes aegypti (Linnaeus). Asian Biomed. 2015;9:313-20.

83. Chin AC, Chen CD, Low VL, Lee HL, Azidah AA, Lau KW, et al. Comparative efficacy of commercial mosquito coils against Aedes aegypti (Diptera: Culicidae) in Malaysia: a nationwide report. J Econ Entomol. 2017;110:2247-51.

84. Rohani A, Suzilah I, Malinda M, Anuar I, Mohd Mazlan I, Salmah Maszaitun $\mathrm{M}$, et al. Aedes larval population dynamics and risk for dengue epidemics in Malaysia. Trop Biomed. 2011;28:237-48.

85. Aung TT, Win S, Aung S. Status report on epidemiology of dengue/ dengue haemorrhagic fever in Myanmar, 1995. Dengue Bull. 1996;20:41-5.

86. Oo T, Storch V, Madon MB, Becker N. Factors influencing the seasonal abundance of Aedes (Stegomyia) aegypti and the control strategy of dengue and dengue haemorrhagic fever in Thanlyin Township, Yangon City, Myanmar. Trop Biomed. 2011;28:302-11.

87. Powell JR, Tabachnick WJ. History of domestication and spread of Aedes aegypti - a review. Mem Inst Oswaldo Cruz. 2013;108:11-7.

88. Johnsen RE. Preliminary studies of mosquito resistance to insecticides in the Philippines. Mosq News. 1967;27:22-6.

89. Madarieta SK, Salarda A, Benabaye MRS, Tangle JR. Use of permethrintreated curtains for control of Aedes aegypti in the Philippines. Dengue Bull. 1999:23:51-4.

90. Lim KA, Rudnick A, Chan YC. Recent studies of hemorrhagic fevers in Singapore. Singapore Med J. 1961;2:158-61.

91. Tan BT, Lawther JF, Lam-Phua SG, Lee KM. Research in Aedes control. In: Goh KT, editor. Dengue in Singapore. Singapore: WHO Collaborating Centre for Environmental Epidemiology, Ministry of Environment; 1998, p. 124-137.

92. Lee RML, Choong CTH, Goh BPL, Ng LC, Lam-Phua SG. Bioassay and biochemical studies of the status of pirimiphos-methyl and cypermethrin resistance in Aedes (Stegomyia) aegypti and Aedes (Stegomyia) albopictus (Diptera: Culicidae) in Singapore. Trop Biomed. 2014;31:670-9.

93. Pang SC, Chiang LP, Tan CH, Vythilingam I, Lam-Phua SG, Ng LC. Low efficacy of delthamethrin-treated net against Singapore Aedes aegypti is associated with kdr-type resistance. Trop Biomed. 2015;32:140-50. 
94. Hirata K, Komagata O, Itokawa K, Yamamoto A, Tomita T, Kasai S. A single crossing-over event in voltage-sensitive $\mathrm{Na}+$ channel genes may cause critical failure of dengue mosquito control by insecticides. PLoS Negl Trop Dis. 2014:8:e3085.

95. Sheppard PM, Macdonald WW, Tonn RJ, Grab B. The dynamics of an adult population of Aedes aegypti in relation to dengue haemorrhagic fever in Bangkok. J Anim Ecol. 1969;38:661-702.

96. Thanispong K, Sathantriphop S, Chareonviriyaphap T. Insecticide resistance of Aedes aegypti and Culex quinquefasciatus in Thailand. J Pestic Sci. 2008;33:351-6.

97. Sathantriphop S, Paeporn P, Supaphathom K. Detection of insecticides resistance status in Culex quinquefasciatus and Aedes aegypti to four major groups of insecticides. Trop Biomed. 2006;23:97-101.

98. Chadwick PR, Invest JF, Bowron MJ. An Example of cross-resistance to pyrethroids in DDT-resistant Aedes aegypti. Pest Manag Sci. 1977;8:618-24.

99. Somboon P, Prapanthadara LA, Suwonkerd W. Insecticide susceptibility tests of Anopheles minimus s.l., Aedes aegypti, Aedes albopictus, and Culex quinquefasciatus in northern Thailand. Southeast Asian J Trop Med Pub Health. 2003;34:87-93.

100. Ponlawat A, Scott JG, Harrington LC. Insecticide susceptibility of Aedes aegypti and Aedes albopictus across Thailand. J Med Entomol. 2005;42:821-5.

101. Paeporn P, Supaphathom K, Srisawat R, Komalamisra N, Deesin V, Yaumphan $P$, et al. Biochemical detection of pyrethroid resistance mechanism in Aedes aegypti in Ratchaburi Province, Thailand. Trop Biomed. 2004;21: 145-51.

102. Chuaycharoensuk T, Juntarajumnong W, Boonyuan W, Bangs MJ, Akratanakul P, Thammapalo S, et al. Frequency of pyrethroid resistance in Aedes aegypti and Aedes albopictus (Diptera: Culicidae) in Thailand. J Vector Ecol. 2011:36:204-12.

103. Katsuda $Y$, Leemingsawat $S$, Thongrungkiat $S$, Komalamisara N, Kanzaki T, Watanabe T, et al. Control of mosquito vectors of tropical infectious diseases: (1) Bioefficacy of mosquito coils containing several pyrethroids and a synergist. Southeast Asian J Trop Med Pub Health. 2008:39:48-54.

104. Katsuda $Y$, Leemingsawat $S$, Thongrungkiat S, Prummonkol S, Samung $Y$, Kanzaki T, et al. Control of mosquito vectors of tropical infectious diseases: (2) Pyrethroid susceptibility of Aedes aegypti (L.) collected from different sites in Thailand. Southeast Asian J Trop Med Pub Health. 2008:39:229-34.

105. Katsuda Y, Leemingsawat S, Thongrungkiat S, Prummonkol S, Samung Y, Kanzaki T, et al. Control of mosquito vectors of tropical infectious diseases: (3) Susceptibility of Aedes aegypti to pyrethroid and mosquito coils. Southeast Asian J Trop Med Pub Health. 2009;40:929-36.

106. Chadwick PR. The activity of some pyrethroids, DDT and lindane in smoke from coils for biting inhibition, knockdown and kill of mosquitoes (Diptera, Culicidae). Bull Entomol Res. 1975;65:97-107.

107. Stenhouse SA, Plernsub S, Yanola J, Lumjuan N, Dantrakool A, Choochote W, et al. Detection of the V1016G mutation in the voltage-gated sodium channel gene of Aedes aegypti (Diptera: Culicidae) by allele-specific PCR assay, and its distribution and effect on deltamethrin resistance in Thailand. Parasit Vectors. 2013;6:253.

108. Yanola J, Somboon P, Walton C, Nachaiwieng W, Prapanthadara LA. A nove F1552/C1552 point mutation in the Aedes aegypti voltage-gated sodium channel gene associated with permethrin resistance. Pestic Biochem Phys. 2010;96:127-31.

109. Plernsub S, Saingamsook J, Yanola J, Lumjuan N, Tippawangkosol P, Sukontason $\mathrm{K}$, et al. Additive effect of knockdown resistance mutations, S989P, V1016G and F1534C, in a heterozygous genotype conferring pyrethroid resistance in Aedes aegypti in Thailand. Parasit Vectors. 2016;9:417.

110. Plernsub S, Saingamsook J, Yanola J, Lumjuan N, Tippawangkosol P, Walton C, et al. Temporal frequency of knockdown resistance mutations, F1534C and V1016G, in Aedes aegypti in Chiang Mai city, Thailand and the impact of the mutations on the efficiency of thermal fogging spray with pyrethroids. Acta Trop. 2016;162:125-32.

111. Yanola J, Suwan W, Walton C, Lumjuan N, Prapanthadara LA, et al. Enzymesbased resistant mechanism in pyrethroid resistant and susceptible Aedes aegypti strains from northern Thailand. Parasitol Res. 2011;109:531-7.

112. Srisawat R, Komalamisra N, Apiwathnasorn C, Paeporn P, Roytrakul S, Rongsriyam $Y$, et al. Field-collected permethrin-resistant Aedes aegypti from central Thailand contain point mutations in the domain IIS6 of the sodium channel gene ( $k d r)$. Southeast Asian J Trop Med Pub Health. 2012:43:1380-6.

113. Prapanthadara LA, Promtet N, Koottathep S, Somboon P, Suwonkerd W, McCarroll $L$, et al. Mechanisms of DDT and permethrin resistance in Aedes aegypti from Chiang Mai. Thailand. Dengue Bull. 2002;26:185-9.
114. Pethuan S, Jirakanjanakit N, Saengtharatip S, Chareonviriyaphap T, Kaewpa $D$, Rongnoparut $P$. Biochemical studies of insecticide resistance in Aedes (Stegomyia) aegypti and Aedes (Stegomyia) albopictus (Diptera: Culicidae) in Thailand. Trop Biomed. 2007;24:7-15.

115. Choovattanapakorn N, Yanola J, Lumjuan N, Saingamsook J, Somboon P. Characterization of metabolic detoxifying enzymes in an insecticide resistant strain of Aedes aegypti harboring homozygous S989P and V1016G kdr mutations. Med Entomol Zool. 2017;68:19-26.

116. World Health Organization, Special Programme for Research, Training in Tropical Diseases. Dengue: Guidelines for diagnosis, treatment, prevention and control. 2009. http://www.who.int/tdr/publications/documents/ dengue-diagnosis.pdf

117. Whelan P, Petitt W. An assessment for AusAID and Timor Leste Dengue Mosquito Control Assessment, 13-15 April 2005. Dili, Timor Leste. Darwin, Northern Territory: Department of Health and Community Services; 2007.

118. Frances SP, Morton CJ, Pettit WJ. Studies of the susceptibility of Aedes aegypti (Diptera: Culicidae) from Timor-Leste to pyrethroid and organophosphate insecticides. Austral Entomol. 2016;55:303-7.

119. Mihov C, Tuong CV, Tuong HP. A propos d'une épidémie du type des fièvres hémorragiques à Hanoi. Focia Medica. 1959;1:169-73.

120. Halstead SB, Voulgaropoulos E, Tien NH, Udomsakdi S. Denque hemorrhagic fever in South Vietnam: report of the 1963 outbreak. Am J Trop Med Hyg. 1965;14:819-30.

121. Stanton AT. The mosquitos of far eastern ports with special reference to the prevalence of Stegomyia fasciata. Bull Entomol Res. 1920;10:333-44.

122. Huong VD, Ngoc NTB. Susceptibility of Aedes aegypti to insecticides in South Vietnam. Dengue Bull. 1999;23:85-8.

123. Huber K, Le Loan L, Hoang TH, Tien TK, Rodhain F, Failloux AB. Aedes aegypti in South Vietnam: ecology, genetic structure, vectorial competence and resistance to insecticides. Southeast Asian J Trop Med Pub Health. 2003;34:81-6.

124. Huong VD, Ngoc NTB, Hien DT, Lien B, Thi N. Susceptibility of Aedes aegypti to insecticides in Vietnam. Dengue Bull. 2004;28:179-83.

125. Kawada H, Higa Y, Nguyen YT, Tran SH, Nguyen HT, Takagi M. Nationwide investigation of the pyrethroid susceptibility of mosquito larvae collected from used tires in Vietnam. PLoS Negl Trop Dis. 2009;3:e391.

126. Kawada H, Higa Y, Komagata O, Kasai S, Tomita T, Yen NT, et al. Widespread distribution of a newly found point mutation in voltage-gated sodium channel in pyrethroid-resistant Aedes aegypti populations in Vietnam. PLoS Negl Trop Dis. 2009;3:e527.

127. Pasteur Institute. Epidemiological and virological vector surveillances for dengue control program in Southern Vietnam. 2008.

128. García GP, Flores AE, Fernández-Salas I, Saavedra-Rodríguez K, Reyes-Solis G, Lozano-Fuentes $S$, et al. Recent rapid rise of a permethrin knock down resistance allele in Aedes aegypti in Mexico. PLoS Negl Trop Dis. 2009;3:e531.

129. Lee C, Vythilingam I, Chong CS, Razak MAA, Tan CH, Liew C, et al. Gravitraps for management of dengue clusters in Singapore. Am J Trop Med Hyg. 2013:88:888-92.

130. Kittayapong $P$, Thongyuan S, Olanratmanee $P$, Aumchareoun W, Koyadun S, Kittayapong $\mathrm{R}$, et al. Application of eco-friendly tools and eco-bio-social strategies to control dengue vectors in urban and peri-urban settings in Thailand. Pathog Glob Health. 2012;106:446-54.

131. Ponlawat A, Fansiri T, Kurusarttra S, Pongsiri A, McCardle PW, Evans BP, et al. Development and evaluation of a pyriproxyfen-treated device to control the dengue vector, Aedes aegypti (L.) (Diptera: Culicidae). Southeast Asian J Trop Med Pub Health. 2013;44:167-78.

132. Lau SM, Vythilingam I, Doss II, Sekaran SD, Chua TH, Sulaiman W, et al. Surveillance of adult Aedes mosquitoes in Selangor, Malaysia. Trop Med Int Health. 2015;20:1271-80.

133. Lazaro A, Han WW, Manrique-Saide P, George L, Velayudhan R, Toledo J, et al. Community effectiveness of copepods for dengue vector control: systematic review. Trop Med Int Health. 2015;20:685-706.

134. Tun-Lin W, Lenhart A, Nam VS, Rebollar-Téllez E, Morrison AC, Barbazan P, et al. Reducing costs and operational constraints of dengue vector control by targeting productive breeding places: a multi-country non-inferiority cluster randomized trial. Trop Med Int Health. 2009;14:1143-53.

135. Saiful AN, Lau MS, Sulaiman S, Hidayatulfathi O. Residual effects of TMOF-Bti formulations against 1st instar Aedes aegypti Linnaeus larvae outside laboratory. Asian Pac J Trop Biomed. 2012;2:315-9.

136. Jeyaprakash A, Hoy MA. Long PCR improves Wolbachia DNA amplification: wsp sequences found in $76 \%$ of sixty-three arthropod species. Insect Mol Biol. 2000;9:393-405. 
137. Vythilingam I, Sam JI, Chan YF, Khaw LT, Sulaiman WYW. New paradigms for virus detection, surveillance and control of Zika virus vectors in the settings of Southeast Asia. Front Microbiol. 2016;7:1452.

138. Hoffmann AA, Montgomery BL, Popovici J, Iturbe-Ormaetxe I, Johnson PH, Muzzi F, et al. Successful establishment of Wolbachia in Aedes populations to suppress denque transmission. Nature. 2011;476(7361):454-7.

139. Nguyen TH, Le Nguyen H, Nguyen TY, Vu SN, Tran ND, Le TN, et al. Field evaluation of the establishment potential of w MelPop Wolbachia in Australia and Vietnam for dengue control. Parasit Vectors. 2015;8:563.

140. Rašić G, Endersby-Harshman N, Tantowijoyo W, Goundar A, White V, Yang $\mathrm{Q}$, et al. Aedes aegypti has spatially structured and seasonally stable populations in Yogyakarta, Indonesia. Parasit Vectors. 2015;8:610

141. Lau KW, Chen CD, Lee HL, Norma-Rashid Y, Sofian-Azirun M. Evaluation of insect growth regulators against field-collected Aedes aegypti and Aedes albopictus (Diptera: Culicidae) from Malaysia. J Med Entomol. 2015;52:199-206.

142. World Health Organization. Instructions for determining the susceptibility or resistance of adult mosquitoes to organochlorine, organophosphate and carbamate insecticides: establishment of the baseline. Geneva, Switzerland: World Health Organization; 1981.

143. World Health Organization. Vector resistance to pesticides. Fifteenth report of the WHO expert committee on vector biology and control. Geneva, Switzerland: World Health Organization; 1992.

144. World Health Organization. Monitoring and managing insecticide resistance in Aedes mosquito populations: Interim guidance for entomologists. Geneva, Switzerland: World Health Organization; 2016.

Ready to submit your research? Choose BMC and benefit from:

- fast, convenient online submission

- thorough peer review by experienced researchers in your field

- rapid publication on acceptance

- support for research data, including large and complex data types

- gold Open Access which fosters wider collaboration and increased citations

- maximum visibility for your research: over $100 \mathrm{M}$ website views per year

At BMC, research is always in progress.

Learn more biomedcentral.com/submissions 